\title{
Coronary surgery in women: How can we improve outcomes
}

\author{
Brittany A. Zwischenberger, MD, ${ }^{\mathrm{a}}$ Oliver K. Jawitz, MD, ${ }^{\mathrm{a}}$ and Jennifer S. Lawton, $\mathrm{MD}^{\mathrm{b}}$
}

This Invited Expert Opinion is based on the presentation by Dr Jennifer Lawton at the 2021 American Association for Thoracic Surgery Meeting, International Coronary Congress Session. In this opinion, we consider the factors that contribute to the differences in outcomes after coronary artery bypass grafting $(\mathrm{CABG})$ between women and men to provide strategies to optimize outcomes in women.

Data to adequately inform coronary artery revascularization in women are limited. The initial data available to inform the treatment of women with coronary artery disease were based on randomized controlled trials that evaluated outcomes only in men. ${ }^{1,2}$ Women have had lower rates of CABG compared with men $(\sim 13 \%-16 \%$ in the late $1970 \mathrm{~s}^{3,4}$ ) to $29 \%$ in $2014 .{ }^{5}$ In addition, there was a greater relative decline in the use of CABG in women between 1999 until $2014(66 \%$ decline in women vs $60 \%$ in men). ${ }^{5}$ Thus, treatment decisions for women with coronary artery disease have been based on data that are limited and may not be applicable, appropriate, or optimal.

Fortunately, to ensure that the National Institutes of Health (NIH) is funding the highest quality science, the NIH now requires that rigor and transparency be addressed in every grant application submitted. This information requires a response to the consideration of relevant biological variables, including sex. The NIH states that "sex is a biological variable that is frequently ignored in animal studies and analyses, leading to an incomplete understanding of potential sex-based differences in basic biological function, disease processes and treatment response" and that "strong justification from the scientific literature, preliminary data, or relevant considerations be provided for applications proposing to study only one sex." ${ }^{, 6}$ The goal of this requirement is to increase the use of female animals in basic science experiments as well as to increase the number of women enrolled in clinical trials to inform the best clinical care.

\footnotetext{
From the a Division of Cardiovascular and Thoracic Surgery, Department of Surgery, Duke University Medical Center, Baltimore, Md; and ${ }^{\mathrm{b}}$ Division of Cardiac Surgery, Department of Surgery, Johns Hopkins University, Baltimore, Md.

Received for publication Sept 26, 2021; accepted for publication Sept 27, 2021; available ahead of print Oct 2, 2021.

Address for reprints: Jennifer S. Lawton, MD, Division of Cardiac Surgery, Department of Surgery, Johns Hopkins School of Medicine, 1800 Orleans St, Zayed 7107, Baltimore, MD 21287 (E-mail: jlawton4@jhmi.edu).

JTCVS Techniques 2021;10:122-8

2666-2507

Copyright (C) 2021 The Author(s). Published by Elsevier Inc. on behalf of The American Association for Thoracic Surgery. This is an open access article under the CC BY-NC-ND license (http://creativecommons.org/licenses/by-nc-nd/4.0/). https://doi.org/10.1016/j.xjtc.2021.09.051
}

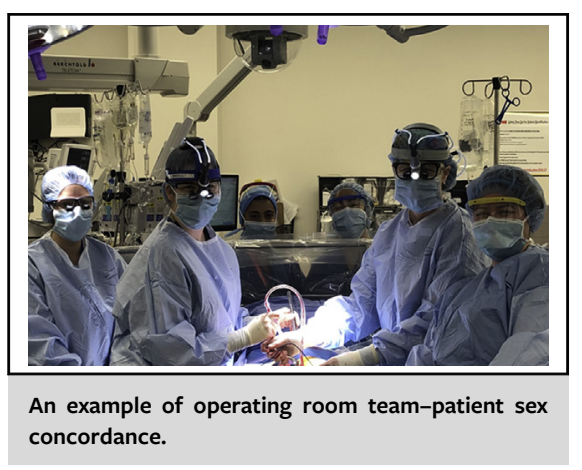

\begin{abstract}
CENTRAL MESSAGE
Strategies must be developed to reduce mortality in women undergoing $C A B G$ with a focus on unique risk factor treatment, inclusion of women in research, and adherence to guidelinedirected care for all.
\end{abstract}

See Commentaries on pages 129 and 131.

\section{WOMEN ARE DIFFERENT FROM MEN}

Cardiovascular disease (CVD) remains the number one killer of women, and more women than men died of CVD between 1984 and 2012 (Figure 1). ${ }^{7}$ Women have unique cardiovascular risk factors, including gestational diabetes, preterm delivery under 37 weeks gestation, hypertensive disorders of pregnancy, autoimmune disease, and breast cancer treatment. Diabetes and depression may be more powerful risk factors in women than in men..$^{8-10}$

In addition, women tend to present with CVD at an age that is 10 years older than men, are more likely to have atypical symptoms of angina, are more likely to have multiple risk factors and comorbidities, present more often with silent myocardial infarction and sudden death, are more likely to die within 1 year after myocardial infarction, are more likely to have emergency presentation and a more severe angina class, have greater disabling symptoms despite less extensive $\mathrm{CAD}$, are less likely to undergo electrocardiography, cardiac catheterization, or revascularization, are less likely to receive antiplatelet drugs, beta-blockers, angiotensin-converting enzyme inhibitors 


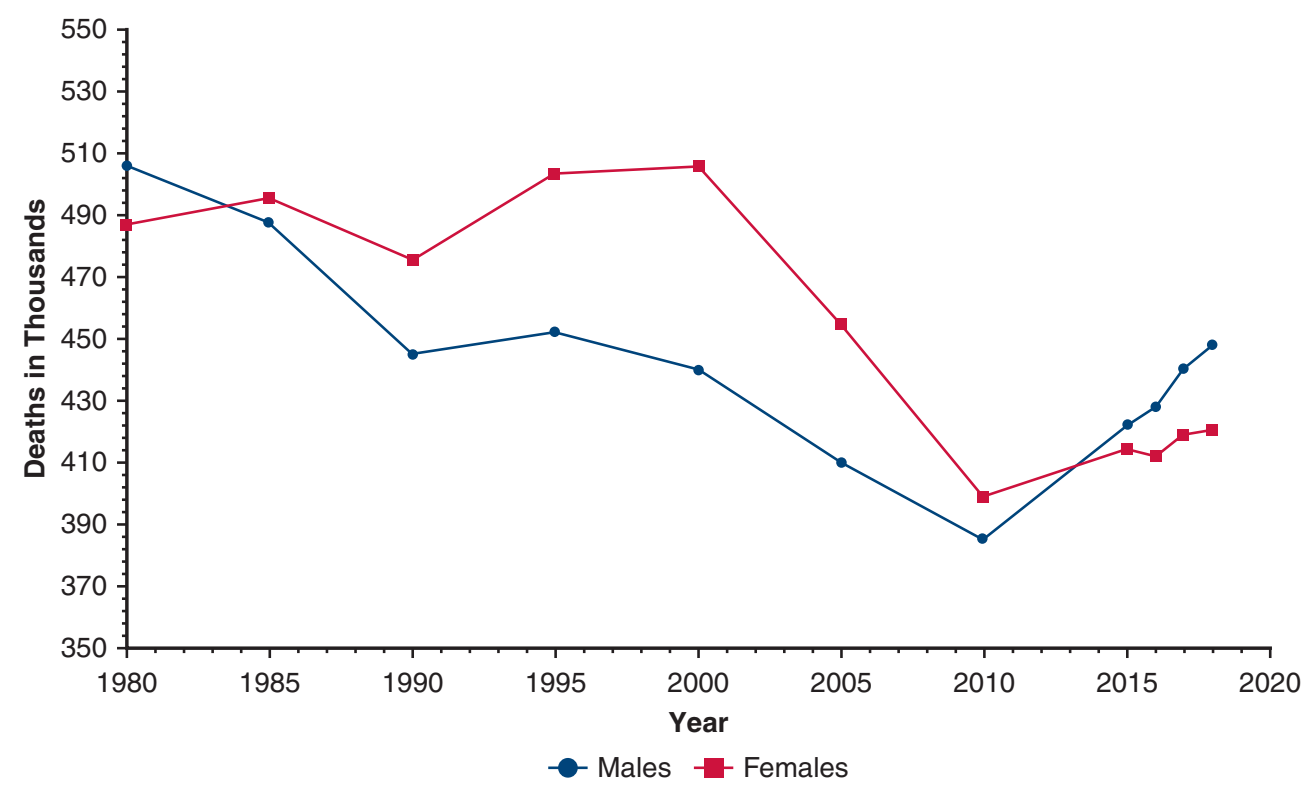

FIGURE 1. CVD mortality trends for US men and women 1980 to 2018. More women than men died of CVD between 1984 and 2012. Reproduced from Virani SS, Alonso A, Benjamin EJ, Bittencourt MS, Callaway CW, Carson AP, et al. Heart Disease and Stroke Statistics - 2020 Update: A Report from the American Heart Association. Circulation. 2020:141:9:e139-e596. License \# 5143200959123, September 6, 2021, Licensed Content publisher: Wolters Kluwer Health, Inc.

or statins, and are less likely to be referred for cardiac rehabilitation compared with men. $8,9,11-14$

Thus, because women tend to be different from men who present for $\mathrm{CABG}$, propensity matching women who undergo CABG with men has been challenging, with only $26 \%$ of women and only $8 \%$ of men matched in one study, ${ }^{15-17}$ and unique and specific gender profiling has been described for women to highlight differences from men. ${ }^{18}$

In the past, the lack of physician knowledge regarding risk factors in women and the classification of women at a lower risk category for CVD than men despite a similar calculated risk have led to the under-recognition and treatment of women with CVD. ${ }^{8}$

Knowledge of the unique risk factors and presentation of women with CVD will provide earlier diagnosis and potentially improve revascularization options and outcomes. This is vital because CABG remains the revascularization of choice in patients with complex left main coronary artery disease (CAD), complex multivessel CAD (especially in patients with diabetes mellitus), and reduced left ventricular function.

\section{OPERATIVE MORTALITY IN WOMEN COMPARED WITH MEN}

Many unadjusted observational studies comparing operative mortality between women and men have suggested higher operative mortality in women undergoing CABG. ${ }^{19-21}$ However, observational studies with risk factor adjustment demonstrate contradictory findings, ${ }^{13-22}$ and propensity-matched comparisons have demonstrated no difference in operative mortality between matched pairs of women and men. ${ }^{16,17}$

In 3 large contemporary reports (ranging from 1.8 to 3.8 million patients each), women comprised a lower percentage of overall CABG use and a higher operative mortality after CABG. ${ }^{5,23,24}$ Using the National Inpatient Sample database, Mahowald and colleagues ${ }^{24}$ demonstrated a consistently higher in-hospital mortality before and after propensity matching in women undergoing CABG after myocardial infarction, compared with men between 2003 and 2016 in 3.6 million patients (33\% women). Also using the National Inpatient Sample, Mohamed and colleagues ${ }^{24}$ found declining mortality in all patients ( 2.5 million, $28 \%$ women) over time (2004-2015) after CABG; however, mortality was persistently higher in women, even after adjustment for risk factors, and women had a $43 \%$ increased odds of mortality compared with men. ${ }^{23}$ In 1.8 million Medicare beneficiaries between 1999 and 2014, Angraal and colleagues ${ }^{5}$ found that women consistently had a lower rate of CABG use and higher in-hospital, 30-day, and 1-year mortality compared with men for all years evaluated. Therefore, summarizing the more contemporary and larger studies, we must conclude that women have a higher mortality compared with men undergoing CABG.

\section{DIFFERENCES IN MORTALITY RELATED TO PATIENT DIFFERENCES AND SURGICAL STRATEGIES}

The difference noted in mortality between women and men is likely multifactorial. As surgeons, it is imperative 
for us to determine if perioperative factors are in part responsible and if we can alter any potential biases and practices.

In 2005, the Society of Thoracic Surgeons (STS) published practice guidelines for CABG in women. ${ }^{25}$ These guidelines included recommendations to use of at least 1 internal thoracic artery (ITA), maintain perioperative blood glucose levels in the range of 100 to $150 \mathrm{mg} / \mathrm{dL}$, maintain adequate intraoperative hematocrit levels, tailor anesthetic management and sedation to body size, maintain a euthyroid state in hypothyroid women during surgery, and do not use hormone replacement therapy in postmenopausal women. ${ }^{25}$

We systematically evaluate the preoperative, intraoperative, and postoperative phases of care in women undergoing CABG in an effort to identify potential strategies to optimize care. Use of guideline-directed therapy (evidence-based medicine) for all phases of care is obvious, but warrants stating.

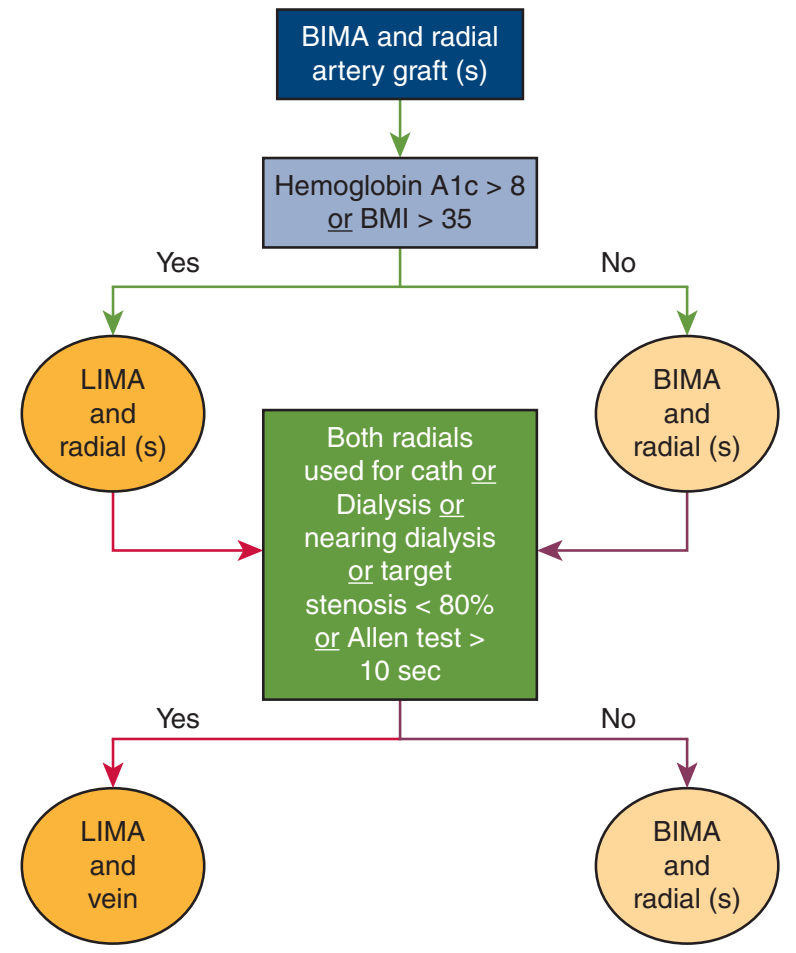

FIGURE 2. Algorithm for use of arterial grafts in women. All arterial grafting should be considered for each patient (regardless of sex) with the use of a simple bedside algorithm that will optimize conduit selection for improved outcomes, as women derive similar benefits from arterial grafting as men. Adapted from figure from Lawton JS. Commentary: one artery does not fit all: tailoring the operation to the patient. JTCVS Open March 2021. https://www.jtcvsopen.org/article/S2666-2736(20)30211-4/ pdf. BITA, Bilateral internal thoracic artery; BMI, body mass index; LITA, left internal thoracic artery.

\section{PREOPERATIVE STRATEGIES}

It is intuitive that guideline-directed optimal medical therapy should be used before CABG. In the preoperative phase, attention to and optimization of comorbidities such as hypothyroidism and diabetes mellitus are important, as in any patient before CABG. Optimal conduit selection is also important. We should evaluate each patient with the intent to use all arterial grafts, if possible, and this is particularly important in women (Figure 2). ${ }^{26}$ Multiple studies dating back to 1999 have documented lower use of arterial grafts in women, including use of the left internal thoracic artery (LITA), right internal thoracic artery, and radial artery. ${ }^{16,27-31}$ In addition, a higher use of BITA and a greater increase of BITA, 2 arteries, or 3 or more arteries over time has been demonstrated in men compared with women after propensity matching in one study. ${ }^{31}$ Additionally, in 1.2 million patients $(25 \%$ women $)$ undergoing first-time isolated CABG from the STS database from 2011 to 2019 , women were significantly less likely to receive LITA, BITA, or radial grafts, even after adjustment $^{32}$ (Figure 3).

\section{INTRAOPERATIVE STRATEGIES}

Women consistently have been shown to receive fewer grafts and less completeness of revascularization compared with men, ${ }^{16,27,28,33,34}$ which is likely associated with reduced long-term survival. ${ }^{35}$ In the large STS database study mentioned, Jawitz and colleagues ${ }^{32}$ found that female sex was also associated with a lower odds than male sex of undergoing complete revascularization. Thus, deliberate efforts should be made to provide complete revascularization in women.

Large retrospective studies with multivariable regression and propensity matching between women and men have suggested that women who undergo CABG off pump have mortality that is similar to that of men and that women may derive a greater benefit from off pump techniques than men. ${ }^{21,36-39}$ This is consistent with the fact that women are thought to be a high-risk subgroup of all patients undergoing CABG.

Many surgeons cite smaller body size and coronary artery size as reasons why women do not receive arterial grafts or complete revascularization. This reasoning is not intuitive, because off-pump CABG is generally thought to be more technically challenging; thus, why would women then have similar outcomes to those of men with the use of more challenging technique? Also, Vaccarino and colleagues ${ }^{40}$ demonstrated that the mortality difference between men and women decreases with age, yet coronary artery size does not increase with age. Aldea and colleagues $^{28}$ noted that the time to construct a distal anastomosis was similar between women and men, suggesting a similar technical challenge for each anastomosis. 


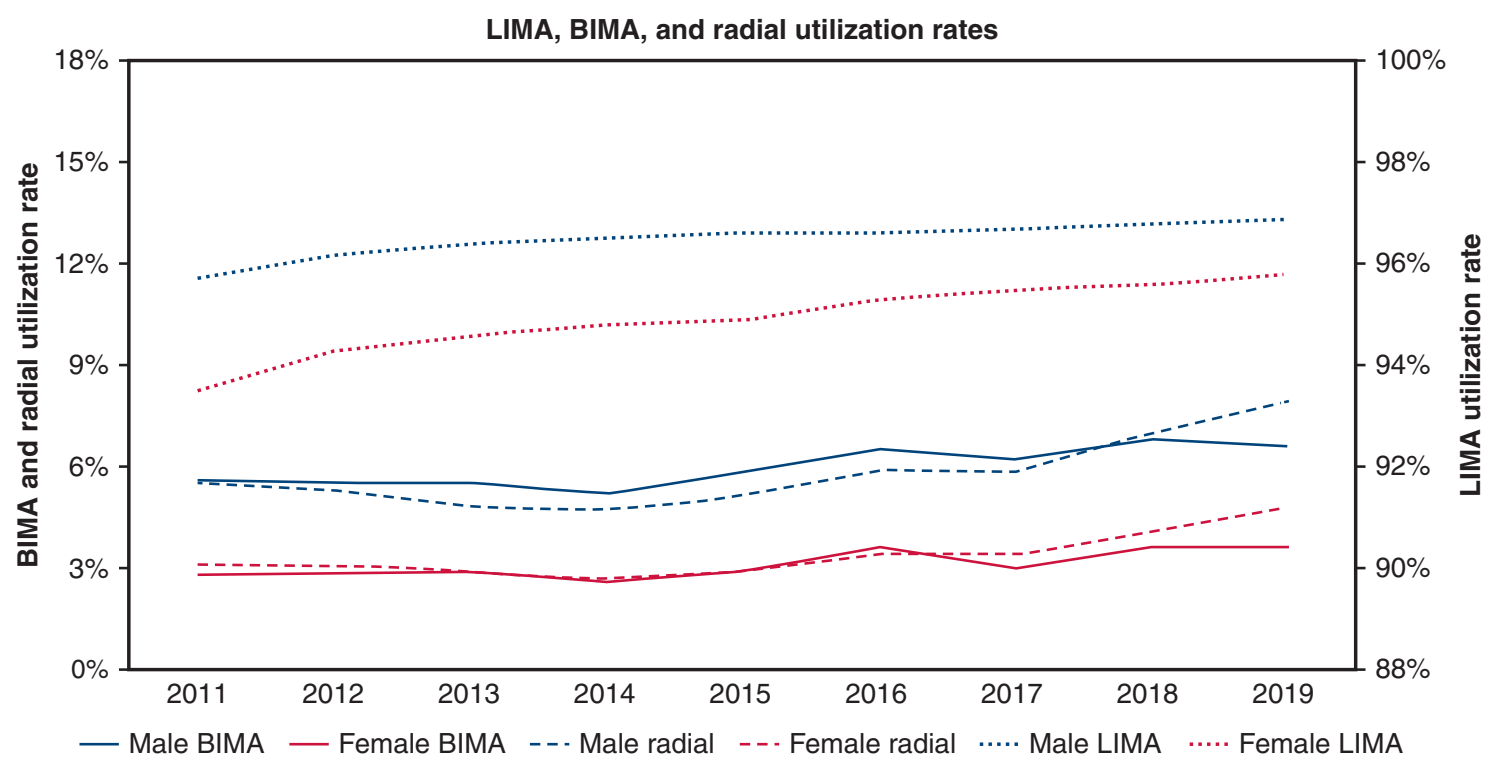

FIGURE 3. Lower use of arterial grafts in women and men Between 2011 and 2019. The graph depicts BITA (solid lines), LITA (dotted lines), and radial artery graft (dashed lines) use in women (red lines) and men (blue lines) undergoing CABG from 2011 to 2019 from the STS database (1,212,487 patients). Y axis on left for BITA and radial use. Y axis on right for LITA use. Use of LITA (95.6\% in men, 93.6\% in women), use of BITA (5.6\% in men, 2.9\% in women), and use of radial artery ( $5.6 \%$ in men, $3.2 \%$ in women) all significantly different $(P<.01)$ after adjustment for male versus female use. Women were less likely to receive a LITA graft with an adjusted odds ratio of $0.79(95 \%$ confidence interval, $0.75-0.83, P<.0001)$, and women were less likely to undergo multiarterial grafting with an adjusted odds ratio 0.78 ( $95 \%$ confidence interval, $0.75-0.81, P<.0001)$. Adaptation of figure from Jawitz OK, Lawton JS, Thibault D, O'Brien S, Higgins RSD, Schena S, et al. Sex differences in coronary artery bypass grafting techniques: a STS database analysis. Ann Thorac Surg. 2021:S0003-4975(21)01250-9. BITA, Bilateral internal thoracic artery; CI, confidence interval; LITA, left internal thoracic artery; OR, odds ratio.

\section{POSTOPERATIVE STRATEGIES}

After CABG, guideline-directed optimal medical therapy and other recommended therapies such as tobacco cessation counseling and cardiac rehabilitation should be prescribed for women, similar to men. The lack of physician awareness regarding unique risk factors in women, the fact that women are less likely to be referred for cardiac rehabilitation, and the underuse of secondary prevention medications in women contribute to suboptimal outcomes. ${ }^{8,12,14}$ Based on the NIH large randomized trial, the Women's Health Initiative and the HERS Trial and HERS II follow Trial, exogenous estrogen administration is a Class III-Harm

TABLE 1. Strategies to reduce mortality in women after coronary artery bypass grafting

Include animals of both sexes in basic science research to understand
physiologic differences
Use guideline-directed optimal medical care
Use guideline-directed revascularization strategies including use of
arterial conduits
Enroll more women in clinical trials
Surgeon specialization in coronary surgery for women
Establish centers for specialization in the treatment of women with
cardiovascular disease

recommendation and should not be prescribed to women for heart disease prevention. ${ }^{12,41,42}$

Beginning in 2004, the American Health Association provided evidence-based guidelines for CVD prevention in women ${ }^{43}$ that can be used to provide optimal care after CABG.

\section{OPTIMIZATION OF OUTCOMES: THE FUTURE}

Many strategies may be used to reduce mortality in women after CABG (Table 1). These include the use of guideline directed optimal medical care, use of guidelinedirected revascularization strategies, enrollment of women in research, surgeon specialization in coronary surgery, and the creation of centers for specialization in the treatment of women with CVD.

The use of guideline-directed optimal medical care is imperative for all patients who undergo CABG. This includes postoperative therapy guided to prevent future cardiovascular events and focus on psychosocial issues. Likewise, the use of guideline-directed revascularization strategies will ensure that women receive beneficial revascularization strategies that will prolong survival and reduce future cardiovascular events. As mentioned, female sex was associated with $14 \%$ to $22 \%$ lower odds of undergoing guideline concordant revascularization including use of LITA, multiarterial grafting, and complete 


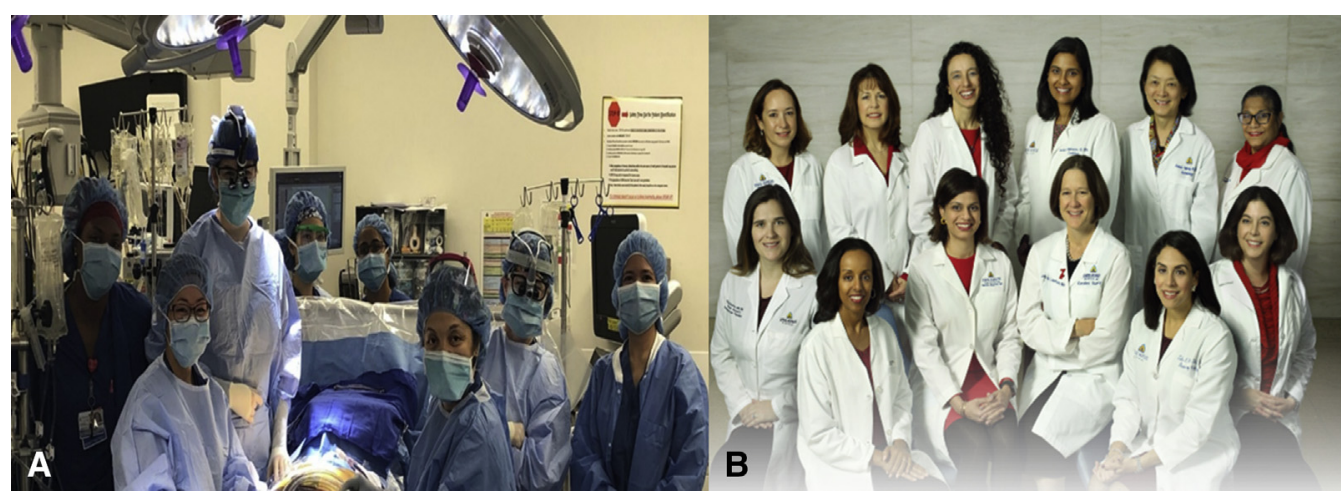

FIGURE 4. Examples of patient and physician sex concordance and sex-specific cardiovascular care. A, Photograph from Dr Lawton's operating room with all female staff: surgeons, perfusionist, nursing, physician assistants, anesthesiologists, and patient. B, Female physicians who treat CVD in women at the Women's Cardiovascular Center, John's Hopkins Hospital and University. Back left to right: Dr Allison Hayes, Dr Julie Miller, Dr Erin Michos, Dr Monica Mukherjee, Dr Pam Ouyang, Dr Shilpi Ahmed; front left to right: Dr Caitlin Hicks, Dr Tigist Hailu, Dr Garima Sharma, Dr Jennifer Lawton, Dr Tala Al-Talib, Dr Wendy Post. Photo by Keith Weller, Johns Hopkins School of Medicine.

revascularization in a large STS database study. ${ }^{32}$ This suboptimal care is not warranted because women have been shown to derive the same benefits as men from these proven strategies: survival benefit to single ITA, BITA, and complete revascularization similar to that in men $^{30,34}$; radial artery protective in women and patency better than vein $^{44}$; and improved survival with radial artery in women. ${ }^{29}$

Women should be enrolled in clinical trials and both sexes of animals should be used in basic science research to adhere to NIH Rigor and Reproducibility recommendations, regardless of funding source. This will add important information that will inform and improve the future care of both women and men with CVD.

Patients who currently present for CABG have more comorbidities and a higher percentage have had percutaneous intervention than in prior years. ${ }^{45-47}$ LaPar and colleagues ${ }^{48}$ suggest that an expected isolated CABG mortality of less than $1 \%$ can be achieved in only $60 \%$ of patients. We propose that surgeon specialization in coronary surgery of women should be considered because surgeons are treating sicker patients while at the same time being faced with mandated transparency, intense scrutiny, and public reporting of outcomes.

Surgeon specialization in coronary surgery has been associated with reduced mortality rate, reduced operative time, increased use of BITA, more distal anastomoses, and improved survival ${ }^{49-51}$ and super specialization within cardiac surgery has been suggested to improve outcomes. ${ }^{52-54}$ By tailoring the operation to the patient and the surgeon, specialized surgeons regularly consider issues relating to quality, they have a desire to improve the status quo, they conduct research in the field, they are more likely to be abreast of the newest literature and technology, they push innovation, they will improve education of trainees, and they will advocate for best practices.
The ultimate specialization is the innovative idea of surgeon and patient sex concordance (female surgeon and female patient) (Figure 4, A). Improved outcomes in patients after myocardial infarction have been described with patient and physician concordance, ${ }^{55}$ and female patients with CVD are more likely to receive guideline-recommended care when treated with a female physician. ${ }^{56}$ Likewise, centers of specialization or the regionalization of optimal care for women with CVD may be beneficial (Figure 4, B). This allows for centralization of services, improved outcomes, and the ability to rescue patients with potentially bad outcomes. $^{57}$

\section{CONCLUSIONS}

To improve outcomes after CABG in women, knowledge of the differences between women and men with CVD is essential, more research is needed in women, and we as surgeons must strive to give all of our patients the best evidence-based medical care.

\section{Conflict of Interest Statement}

The authors reported no conflicts of interest.

The Journal policy requires editors and reviewers to disclose conflicts of interest and to decline handling or reviewing manuscripts for which they may have a conflict of interest. The editors and reviewers of this article have no conflicts of interest.

\section{References}

1. Murphy ML, Hultgren HN, Detre K, Thomsen J, Takaro T. Treatment of chronic stable angina. A preliminary report of survival data of the randomized Veterans Administration cooperative study. N Engl J Med. 1977;297:621-7.

2. Long-term results of prospective randomised study of coronary artery bypass surgery in stable angina pectoris. European Coronary Surgery Group. Lancet. 1982; 2:1173-80.

3. Bolooki H, Vargas A, Green R, Kaiser GA, Ghahramani A. Results of direct coronary artery surgery in women. J Thorac Cardiovasc Surg. 1975;69:271-7. 
4. Tyras DH, Barner HB, Kaiser GC, Codd JE, Laks H, Willman VL. Myocardial revascularization in women. Ann Thorac Surg. 1978;25:449-53.

5. Angraal S, Khera R, Wang Y, Lu Y, Jean R, Dreyer RP, et al. Sex and race differences in the utilization and outcomes of coronary artery bypass grafting among Medicare beneficiaries, 1999-2014. J Am Heart Assoc. 2018;7:e009014.

6. NIH website. Available at: https://grants.nih.gov/policy/reproducibility/ guidance.htm. Accessed July 26, 2021.

7. Benjamin EJ, Virani SS, Callaway CW, Chamberlain AM, Chang AR, Cheng S, et al. American Heart Association Council on Epidemiology and Prevention Statistics Committee and Stroke Statistics Subcommittee. Heart Disease and Stroke Statistics-2018 Update: A Report From the American Heart Association. Circulation. 2018;137:e67-492.

8. Mosca L, Linfante AH, Benjamin EJ, Berra K, Hayes SN, Walsh BW, et al. National study of physician awareness and adherence to cardiovascular disease prevention guidelines. Circulation. 2005;111:499-510.

9. Daly C, Clemens F, Lopez Sendon JL, Tavazzi L, Boersma E, Danchin N, et al; Euro Heart Survey Investigators. Gender differences in the management and clinical outcome of stable angina. Circulation. 2006;113:490-8.

10. Garcia M, Mulvagh SL, Merz CN, Buring JE, Manson JE. Cardiovascular disease in women: clinical perspectives. Circ Res. 2016;118:1273-93.

11. Chandra NC, Ziegelstein RC, Rogers WJ, Tiefenbrunn AJ, Gore JM, French WJ, et al. Observations of the treatment of women in the United States with myocardial infarction: a report from the National Registry of Myocardial Infarction-I. Arch Intern Med. 1998;158:981-8.

12. Hulley S, Grady D, Bush T, Furberg C, Herrington D, Riggs B, et al. Randomized trial of estrogen plus progestin for secondary prevention of coronary heart disease in postmenopausal women. Heart and Estrogen/progestin Replacement Study (HERS) Research Group. JAMA. 1998;280:605-13.

13. Vaccarino V, Parsons L, Every NR, Barron HV, Krumholz HM. Sex-based differences in early mortality after myocardial infarction. National Registry of Myocardial Infarction 2 Participants. N Engl J Med. 1999;341:217-25.

14. Li S, Fonarow GC, Mukamal K, Xu H, Matsouaka RA, Devore AD, et al. Sex and racial disparities in cardiac rehabilitation referral at hospital discharge and gaps in long-term mortality. J Am Heart Assoc. 2018;7:e008088.

15. Koch CG, Khandwala F, Nussmeier N, Blackstone EH. Gender and outcomes after coronary artery bypass grafting: a propensity matched comparison. $J$ Thorac Cardiovasc Surg. 2003;126:2032-43.

16. Parolari A, Dainese L, Naliato M, Polvani G, Loardi C, Trezzi M, et al. Do women currently receive the same standard of care in coronary artery bypass graft procedures as men? A propensity analysis. Ann Thorac Surg. 2008;85: 885-90.

17. Garatti A, Parolari A, Canziani A, Mossuto E, Daprati A, Abu Farah A, et al. Is female sex an independent risk factor for early mortality in isolated coronary artery bypass graft? A propensity-matched analysis. J Cardiovasc Med (Hagerstown). 2018;19:497-502.

18. Koch CG, Khandwala F, Nussmeier N, Blackstone EH. Gender profiling in coronary artery bypass grafting. J Thorac Cardiovasc Surg. 2003;6:2044-51.

19. Edwards FH, Carey JS, Grover FL, Bero JW, Hartz RS. Impact of gender on coronary artery bypass operative mortality. Ann Thorac Surg. 1998;66:125-31.

20. Rogers MAM, Langa KM, Kim C, Nallamothu BK, McMahon LF, Malani PN, et al. Contribution of infection to increased mortality in women after cardiac surgery. Arch Intern Med. 2006;166:437-43.

21. Ter Woorst JF, Hoff AHT, Haanschoten MC, Houterman S, van Straten AHM, Soliman-Hamad MA. Do women benefit more than men from off-pump coronary artery bypass grafting? Neth Heart J. 2019;27:629-35.

22. den Ruijter HM, Haitjema S, van der Meer MG, van der Harst P, Rouleau JL, Asselbergs FW, et al; IMAGINE Investigators. Long-term outcome in men and women after CABG; results from the IMAGINE trial. Atherosclerosis. 2015; 241:284-8.

23. Mohamed W, Mohamed MO, Hirji S, Ouzounian M, Sun LY, Coutinho T, et al. Trends in sex-based differences in outcomes following coronary artery bypass grafting in the United States between 2004 and 2015. Int J Cardiol. 2020;320: $42-8$.

24. Mahowald MK, Alqahtani F, Alkhouli M. Comparison of outcomes of coronary revascularization for acute myocardial infarction in men versus women. Am J Cardiol. 2020;132:1-7.

25. Edwards FH, Ferraris VA, Shahian DM, Peterson E, Furnary AP, Haan CK, et al; Society of Thoracic Surgeons. Gender-specific practice guidelines for coronary artery bypass surgery: perioperative management. Ann Thorac Surg. 2005;79: 2189-94.
26. Lawton JS. Commentary: one artery does not fit all: tailoring the operation to the patient. JTCVS Open March 2021. Available at: https://www.jtcvsopen.org/ article/S2666-273630211-4/pdf. Accessed July 31, 2021.

27. Mickleborough LL, Carson S, Ivanov J. Gender differences in quality of distal vessels: effect on results of coronary artery bypass grafting. J Thorac Cardiovasc Surg. 2003;126:950-8.

28. Aldea GS, Gaudiani JM, Shapira OM, Jacobs AK, Weinberg J, Cupples AL, et al Effect of gender on postoperative outcomes and hospital stays after coronary artery bypass grafting. Ann Thorac Surg. 1999;67:1097-103.

29. Lawton JS, Barner HB, Bailey MS, Guthrie TJ, Moazami N, Pasque MK, et al. Radial artery grafts in women: utilization and results. Ann Thorac Surg. 2005 80:559-63.

30. Attia T, Koch CG, Houghtaling PL, Blackstone EH, Sabik EM, Sabik JF. Does a similar procedure result in similar survival for women and men undergoing isolated coronary artery bypass grafting? J Thorac Cardiovasc Surg. 2017;153: 571-9.

31. Jabagi H, Tran DT, Hessian R, Glineur D, Rubens FD. Impact of gender on arterial revascularization strategies for coronary artery bypass grafting. Ann Thorac Surg. 2018;105:62-8

32. Jawitz OK, Lawton JS, Thibault D, O'Brien S, Higgins RSD, Schena S, et al. Sex differences in coronary artery bypass grafting techniques: a STS database analysis. Ann Thorac Surg. 2021. https://doi.org/10.1016/j.athoracsur.2021.06.039.

33. Ibrahim MF, Paparella D, Ivanov J, Buchanan MR, Brister SJ. Gender-related dif ferences in morbidity and mortality during combined valve and coronary surgery J Thorac Cardiovasc Surg. 2003;126:959-64.

34. Vrancic JM, Navia DO, Espinoza JC, Piccinini F, Camporrotondo M, Benzadon $\mathrm{M}$, et al. Is sex a risk factor for death in patients with bilateral internal thoracic artery grafts? J Thorac Cardiovasc Surg. 2019;158: 1345-53.e1.

35. Melby SJ, Saint LL, Balsara K, Itoh A, Lawton JS, Maniar H, et al. Complete coronary revascularization improves survival in octogenarians. Ann Thorac Surg. 2016;102:505-11.

36. Petro KR, Dullum MK, Garcia JM, Pfister AJ, Qazi AG, Boyce SW, et al. Minimally invasive coronary revascularization in women: a safe approach for a highrisk group. Heart Surg Forum. 2000;3:41-6.

37. Mack MJ, Brown P, Houser F, Katz M, Kugelmass A, Simon A, et al. On-pump versus off-pump coronary artery bypass surgery in a matched sample of women: a comparison of outcomes. Circulation. 2004;110(11 Suppl 1):II1-6.

38. Puskas JD, Kilgo PD, Lattouf OM, Thourani VH, Cooper WA, Vassiliades TA, et al. Off-pump coronary bypass provides reduced mortality and morbidity and equivalent 10-year survival. Ann Thorac Surg. 2008;86:1139-46.

39. Puskas JD, Kilgo PD, Kutner M, Pusca SV, Lattouf O, Guyton RA. Off-pump techniques disproportionately benefit women and narrow the gender disparity in outcomes after coronary artery bypass surgery. Circulation. 2007;116(11 Suppl):I192-9.

40. Vaccarino V, Abramson JL, Veledar E, Weintraub WS. Sex differences in hospital mortality after coronary artery bypass surgery: evidence for a higher mortality in younger women. Circulation. 2002;105:1176-81.

41. Rossouw JE, Anderson GL, Prentice RL, LaCroix AZ, Kooperberg C, Stefanick ML, et al; Writing Group for the Women's Health Initiative Investigators. Risks and benefits of estrogen plus progestin in healthy postmenopausal women: principal results From the Women's Health Initiative randomized controlled trial. JAMA. 2002;288:321-33.

42. Grady D, Herrington D, Bittner V, Blumenthal R, Davidson M, Hlatky M, et al; HERS Research Group. Cardiovascular disease outcomes during 6.8 years of hormone therapy: Heart and Estrogen/progestin Replacement Study follow-up (HERS II). JAMA. 2002;288:49-57.

43. Mosca L, Appel LJ, Benjamin EJ, Berra K, Chandra-Strobos N, Fabunmi RP et al; American Heart Association. Evidence-based guidelines for cardiovascular disease prevention in women. Circulation. 2004;109:672-93.

44. Tam DY, Deb S, Nguyen B, Ko DT, Karkhanis R, Moussa F, et al. The radial artery is protective in women and men following coronary artery bypass grafting-a substudy of the radial artery patency study. Ann Cardiothorac Surg. 2018;7: 492-9.

45. Raza S, Deo SV, Kalra A, Zia A, Altarabsheh SE, Deo VS, et al. Stability after initial decline in coronary revascularization rates in the United States. Ann Thorac Surg. 2019;108:1404-8.

46. Taggart DP. Thomas B. Ferguson Lecture. Coronary artery bypass grafting is still the best treatment for multivessel and left main disease, but patients need to know. Ann Thorac Surg. 2006;82:1966-75. 
47. O’Brien SM, Feng L, He X, Xian Y, Jacobs JP, Badhwar V, et al. The Society of Thoracic Surgeons 2018 Adult Cardiac Surgery Risk Models: Part 2-Statistical Methods and Results. Ann Thorac Surg. 2018;105:1419-28.

48. LaPar DJ, Filardo G, Crosby IK, Speir AM, Rich JB, Kron IL, et al. The challenge of achieving $1 \%$ operative mortality for coronary artery bypass grafting: a multiinstitution Society of Thoracic Surgeons database analysis. J Thorac Cardiovasc Surg. 2010;148:2686-96.

49. Sahni NR, Dalton M, Cutler DM, Birkmeyer JD, Chandra A. Surgeon specialization and operative mortality in United States: retrospective analysis. BMJ. 2016; 354:i3571.

50. Watkins AC, Ghoreishi M, Maassel NL, Wehman B, Demirci F, Griffith BP, et al. Programmatic and surgeon specialization improves mortality in isolated coronary bypass grafting. Ann Thorac Surg. 2018;106:1150-8.

51. Umminger J, Reitz M, Rojas SV, Stiefel P, Shrestha M, Haverich A, et al. Does the surgeon's experience have an impact on outcome after total arterial revascularization with composite T-grafts? A risk factor analysis. Interact Cardiovasc Thorac Surg. 2016;23:749-56.

52. Mack M, Taggart D. Coronary revascularization should be a subspecialty focus in cardiac surgery. J Thorac Cardiovasc Surg. 2019;157:945-7.
53. Mori M, Vega D, Book W, Kogon BE. Heart transplantation in adults with congenital heart disease: $100 \%$ survival in operations performed by a surgeon specializing in congenital heart disease in an adult hospital. Ann Thorac Surg. 2015;99:2173-8.

54. Chancellor WZ, Kron IL. A focused approach: specialization in coronary revascularization. J Thorac Cardiovasc Surg. 2019;157:948-9.

55. Greenwood BN, Carnahan S, Huang L. Patient-physician gender concordance and increased mortality among female heart attack patients. Proc Natl Acad Sci U S A. 2018;115:8569-74.

56. Lau ES, Hayes SN, Volgman AS, Lindley K, Pepine CJ, Wood MJ; American College of Cardiology Cardiovascular Disease in Women Section. Does patient-physician gender concordance influence patient perceptions or outcomes? J Am Coll Cardiol. 2021;77:1135-8.

57. Goldberger ZD, Nallamothu BK. Hospital specialization for coronary artery bypass grafting: anything special about it? Circ Cardiovasc Qual Outcomes. 2010;6:571-2.

Key Words: surgery, coronary artery disease, women 